\title{
Enhancing the bioactivity of polymeric implants by means of cold gas spray coatings
}

\author{
M. Gardon, ${ }^{1}$ H. Melero, ${ }^{1,2}$ N. Garcia-Giralt, ${ }^{2}$ S. Dosta, ${ }^{1}$ I. G. Cano, ${ }^{1}$ J. M. Guilemany ${ }^{1}$ \\ ${ }^{1}$ Thermal Spray Centre, CPT, University of Barcelona, Martí i Franquès, 1, 08028 Barcelona, Spain \\ ${ }^{2}$ URFOA, IMIM (Institut Hospital del Mar d'Investigacions Mèdiques), RETICEF, Doctor Aiguader, 80, 08003 Barcelona, Spain
}

Received 4 July 2013; revised 20 January 2014; accepted 10 February 2014

Published online 6 March 2014 in Wiley Online Library (wileyonlinelibrary.com). DOI: 10.1002/jbm.b.33134

\begin{abstract}
Nanostructured anatase coatings were built-up on biocompatible polyetheretherketone (PEEK) by means of cold gas spray (CGS). Titanium layer was previously desposited, which acted as bond coat between PEEK and metal oxide. Semicrystalline polymer was not degraded during the spraying process and starting composition of titanium dioxide was not affected. $\mathrm{TiO}_{2}$ was homogeneously obtained onto CGS Ti layer and completely covered the piece. Primary human
\end{abstract}

osteoblasts were seeded onto biomaterials and in vitro cell experiments provided evidence to confirm that nanostructured anatase coatings deposited by cold gas spray improve the performance of PEEK implants. (c) 2014 Wiley Periodicals, Inc. J Biomed Mater Res Part B: Appl Biomater, 102B: 1537-1543, 2014.

Key Words: cold gas spray, nanostructure, titanium dioxide, titanium, polymer, implant

How to cite this article: Gardon M, Melero H, Garcia-Giralt N, Dosta S, Cano IG, Guilemany JM. 2014. Enhancing the bioactivity of polymeric implants by means of cold gas spray coatings. J Biomed Mater Res Part B 2014:102B:1537-1543.

\section{INTRODUCTION}

Mechanical properties of polyetheretherketone (PEEK) provide enough bone-like stiffness, fatigue, and chemical resistance for being an excellent choice as bone tissue substitute in the biomedical field. ${ }^{1,2}$ Therefore, it has gained much attention in those orthopedic applications where severe load-bearing behavior is imperative. ${ }^{3-5}$ Nevertheless, it is also attributed limited bioactivity to this material; harsh opposition to allow protein adsorption or promote cell adhesion has been found.,

Attempts for improving its bioactivity have been carried out by many authors through distinct routes and materials. ${ }^{8-10}$ Rapid manufacturing processes that could enhance the biological response of PEEK surfaces are urgently welcomed and promoted. In this line, thermal spray techniques have been historically contributing to the state-of-the-art offering high-performance coatings by means of titanium dioxide feedstock. Initial works involved hydroxyapatite $(\mathrm{HA})+\mathrm{TiO}_{2}$ layers which were obtained by atmospheric plasma spray (APS) and high-velocity-oxygen-fuel spray (HVOF). ${ }^{11-13}$ In these cases, plasma jet and combustion flame propelled ceramic particles toward a substrate and were bonded due its total or partial melting. Obtained results in both technologies demonstrated superior mechanical properties. $\mathrm{TiO}_{2}$ decreased mismatch of thermal expansion between coating and substrate. Besides, it acted as obstacle for microcracking propagation induced by stress. Conversely, HA was in command to favour the biocompatibility of the system. In further studies, nanostructured titanium dioxide layers were successfully deposited using HVOF and applied as implants. ${ }^{14-16}$ Enlarge the specific surface of titanium dioxide by means of nanostructured grains improves protein adsorption, which leads to increased adhesion of the osteoblasts. Thus, satisfactory results related to cell proliferation were attributed to nanoroughness of the metal oxide. At this point titanium dioxide was not behaving anymore as passive material being attractive because of the contribution of its mechanical properties, but was playing a functional task due to its role in the interaction with proteins. In any case, temperature involved in above mentioned processes could increase the grain size of $\mathrm{TiO}_{2}$ and would reduce specific surface of the solid for finally decreasing adsorption of organic molecules on the implant surface.

On the other hand, cold gas spray (CGS) accelerates feedstock powder by means of nitrogen stream and does not require temperature for building-up the coatings, which could assure a higher amount of low-sized metastable $\mathrm{TiO}_{2}$ grains. ${ }^{17,18}$ Thus, deposit homogeneous nanostructured $\mathrm{TiO}_{2}$ layers by CGS would improve the final performance of PEEK implants. Nevertheless, it is not so straightforward to develop a continuous layer of hard and fragile $\mathrm{TiO}_{2}$ due to the impossibility of ceramic particles to deform plastically at the impact, which is the main bonding mechanism in CGS for building-up metallic coatings. With the purpose of solving this issue, it was used anatase powder in this work designed to create chemical bonds with the substrate and among particles at the impact easing the development of the coating. ${ }^{19}$ 


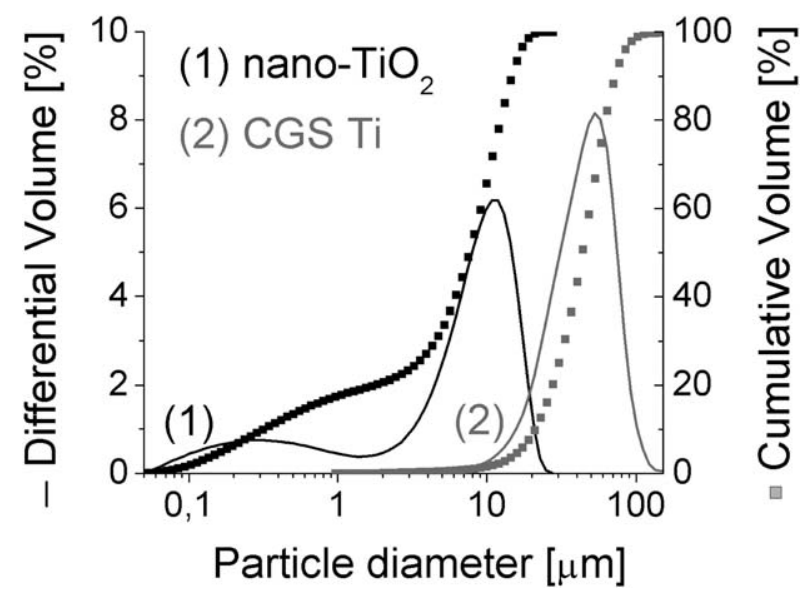

FIGURE 1. Particle size distribution of nano- $\mathrm{TiO}_{2}$ (a) and $\mathrm{Ti}$ (b) powder.

\section{MATERIAL AND METHODS}

\section{Coating development and characterization}

Titanium powder obtained from a fused and crushed process was used as feedstock. The CGS equipment used for obtaining the coatings was a KINETICS ${ } 4000$ (Cold Gas Technology, Ampfing, Germany), with a maximum operating pressure of 40 bar, temperature of $800^{\circ} \mathrm{C}$ and it operated with nitrogen as the propellant gas. In addition, KINETICS $®$ 4000 had the possibility of using a prechamber of $120 \mathrm{~mm}$ in length connected to the nozzle of the gun where powders are heated up for a longer time. Powder and cross-section area of the samples were observed by Scanning Electron Microscopy, SEM (ProX Phenom) using 20 kV. Sample preparation for transmission electron microscopy, TEM (Hitachi H-8000) observation was first based on embedding the powder into an epoxy resin, which was cut and grinded. Then, it was polished obtaining a thiner sample and fixed in a $\mathrm{Cu}$ grid for afterwards carrying out ion milling using an Ar ion beam ( $4 \mathrm{kV}, 0.5 \mathrm{~mA})$. The phase composition of the substrate and coatings was analyzed by the equipment X'Pert PRO MPD diffractometer (PANalytical) with work power of $45 \mathrm{kV}-40 \mathrm{~mA}$ and $\mathrm{Cu} \mathrm{K \alpha}{ }^{1}$ radiation $(\lambda=1.5406$ $\AA$ ); $\theta / 2 \theta$ scan from 4 to $100^{\circ} 2 \theta$ with step size of $0.017^{\circ}$ and measuring time of $50 \mathrm{~s}$ per step. Roughness was analyzed using a profilometer SJ-210 (Mitutoyo); 10 linescan of $1 \mathrm{~cm}$ were carried out for each sample.

\section{Cell culture}

Human osteoblastic cells were obtained from trabecular bone dissected after knee replacement according to the protocol described by Nacher et al. ${ }^{20}$ The study was conducted in accordance with the 1975 Declaration of Helsinki, as revised in 1983, and approved by our local Ethics Committee. All patients submitted written informed consent before their inclusion in the study. Tested samples were placed on a 24-well polystyrene culture plate (Nunc A/S) containing Dulbecco's modified Eagle's medium (DMEM) containing 4.5 $\mathrm{g} \mathrm{L}^{-1}$ glucose and supplemented with $10 \%$ FBS, pyruvate $(1 \mathrm{~m} M)$, glutamine $(2 \mathrm{mM})$, penicillin (100 UI $\left.\mathrm{mL}^{-1}\right)$, strep- tomycin (100 $\mathrm{UI} \mathrm{mL}^{-1}$ ) and ascorbic acid (100 $\mathrm{mg} \mathrm{mL}^{-1}$ ) (Invitrogen), and seeded with 10,000 cells per sample for viability and proliferation studies and 20,000 cells per sample for differentiation studies. Three materials were tested: (i) PEEK; (ii) CGS Ti coating and; (iii) CGS nano-TiO ${ }_{2}$ coating. Next day after seeding, specimens were changed to a new well in order to discard non-adhered cells. Cell assays were carried out for seven samples per case after 1, 3, and 7 days of culture. Seeded surfaces were also observed by SEM at different times of culture after cell fixation by glutaraldehyde diluted in cacodylate buffer, then critical point drying. Negative controls (materials without cells) and positive controls (cells seeded directly on PS) were employed.

\section{Cell adhesion and viability assay}

Live cells reduce water-soluble yellow colored 3-(4,5-dimethylthiazol-2-yl)-2,5-diphenyltetrazoliumbromide (MTT) to a water-insoluble purple colored formazan product. $^{21}$ To analyze cell viability following this principle, a MTT colorimetric assay kit (Roche Diagnostics $\mathrm{GmbH}$ ) was employed, which solubilizes the crystals before the measurement in a scanning multi-well spectrophotometer (ELISA reader) at $550 \mathrm{~nm}$ (reference wavelength $>650 \mathrm{~nm}$ ).

\section{Cell proliferation assay}

The 5-bromo-2'-deoxyuridine (BrdU) incorporated into cellular DNA during cell proliferation is detected using a peroxidase-conjugated anti-BrdU antibody. A BrdU colorimetric immunoassay kit (Roche Diagnostics $\mathrm{GmbH}$ ) was employed according to the manufacturer instructions. The reaction product was quantified by measuring the absorbance using a scanning multiwell spectrophotometer (ELISA reader) at $450 \mathrm{~nm}$ (reference wavelength of $690 \mathrm{~nm}$ ).

\section{Cell differentiation}

Differentiated osteoblasts secrete alkaline phosphatase (ALP), which catalyses the hydrolysis of $p$-nitrophenyl phosphate liberating $p$-nitrophenol and phosphate developing a characteristic yellow color. ALP activity was measured using an Abcam's Alkaline Phosphatase Assay Kit, and the resulting absorbance was also measured using a scanning multiwell spectrophotometer, at $405 \mathrm{~nm}$.

\section{Statistical analyses}

Wilcoxon test was used in order to compare MTT, BrdU and ALP results among tested specimens. Significant $p$ values $<0.05$ are considered significant.

\section{RESULTS AND DISCUSSION}

\section{Coating development}

Cold gas spray may be used for embedding bioactive ceramic particles on a polymeric substrate for its application as implant. ${ }^{22}$ However, it is quite complex to develop homogeneous covering based on this kind of feedstock. Breakdown of the fragile particles at the impact leads to considerable difficulties for building-up of the coating. Recent endeavour provided by TS professionals have led to metal oxide powders able to be deposited by CGS due to its 

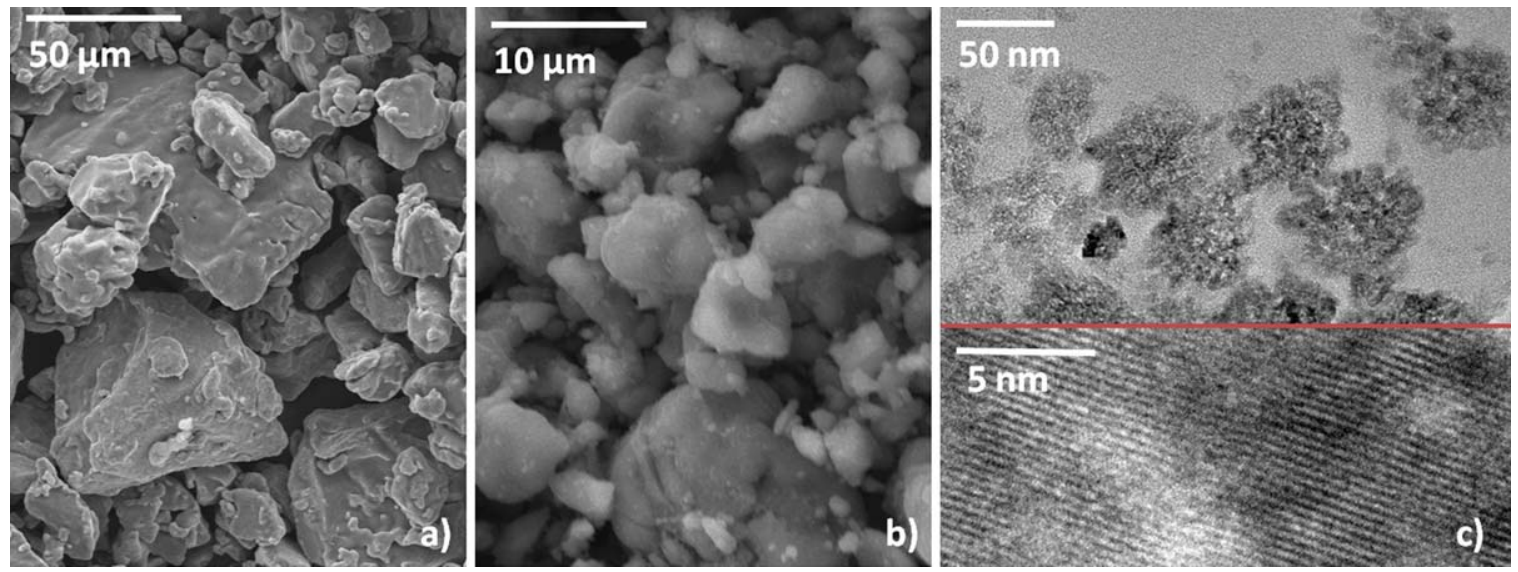

FIGURE 2. SEM micrographs: Ti powder (a), nano- $\mathrm{TiO}_{2}$ powder (b). TEM micrograph: nano-TiO ${ }_{2}$ powder, crystallographic plane is highlighted (c). [Color figure can be viewed in the online issue, which is available at wileyonlinelibrary.com.]

capacity of interacting chemically with the substrate. Therefore, anatase powder designed with this purpose was used in this survey. Figures 1 and 2 show its particle size distribution and also details SEM and TEM micrographs; average particle size was ranged between 20 and $100 \mathrm{~nm}$. Different spraying conditions were tested in order to study the influence of particle velocity and temperature with the polymer through variation of pressure and temperature of nitrogen stream. Nevertheless, unsatisfactory results were obtained. When operating under CGS low energetic conditions, ${ }^{23}$ nanostructured anatase particles did not reach enough velocity for embedding mechanically onto the ductile surface of PEEK. Although ease plastic deformation of the substrate by means of thermal softening is a common procedure selected in CGS, the authors did not provide temperature to the polymer in order to avoid changes in the chemical composition of PEEK. Higher energetic conditions were also tested via increasing gradually pressure and temperature of the propelling gas. Nonetheless, $\mathrm{TiO}_{2}$ particles were detached from the surface and it was not possible either to build-up the ceramic coating or mechanically anchoring the particles into the plastic surface.

In a previous work, CGS Ti coatings were successfully deposited onto PEEK. ${ }^{23}$ Metallic layers were properly bonded obtaining thickness above $1.2 \mathrm{~mm}$. Besides, microRaman spectroscopy confirmed that the polymer was not degraded during the process due to the low temperatures involved. In this study, it was used this Ti layer as bond coat for depositing nanostructured anatase by means of $\mathrm{Ti}$ particles ranging between 20 and $90 \mu \mathrm{m}$ (Figure 1). Metallic lower coating could provide hardness, surface geometry, and chemical composition for easing the adhesion of nano$\mathrm{TiO}_{2}$ particles. ${ }^{24}$ In this case, $2^{2}$ factorial design of experiments was purposed in order to study the influence of gun velocity $\left(v_{\mathrm{g}}\right) /$ stand-off distance $\left(d_{\mathrm{s}}\right)$ and pressure/temperature ratio. Table I summarizes the spraying conditions.

Certain operation parameters provided the adequate balance for adhering nanostructured particles onto titanium (Conditions C353). Neither temperature nor stand-off distance had a deep effect on the coating development in the studied range. On the other hand, pressure critically influenced the deposition of the particles. First, it was possible to observe during the spraying that nano- $\mathrm{TiO}_{2}$ was getting adhered as long as the gun advanced. However, higher pressures gave counterproductive results; previously bonded particles were detached when the nozzle sprayed material closer to an already coated area. Similar consequence was obtained when altering gun velocity. Slower gun velocities increased the number of impacting particles in a given time, which results to initial adhesion of $\mathrm{TiO}_{2}$ and its immediate posterior detachment because of the eroding effect caused by secondary impinging particles. Finally, either pressure or gun velocity were adjusted for effectively bonding anatase. Figure 3 shows cross-section micrographs of both coatings [Figure 3(a,c)], each interface is detailed [Figure 3(b,d)]; both layers are homogeneous and well bonded. Nanotexture of anatase coating adhered onto irregular titanium, where nanostructured metal oxide particles are properly bonded on the rough surface of the CGS Ti layer. It was found a complete coverage of valleys and holes developed by nondramatically deformed titanium particles impigning at the top surface of the bond coat. Both rough surfaces are shown in Figure 4. Surface roughness $\left(R_{\mathrm{a}}\right)$ of the distinct surface materials was measured. Polymer surface was almost completely flat, presenting a roughness value of $0.5 \pm 0.1 \mu \mathrm{m}$. CGS Ti layers presented an irregular surface with sharp peaks whose roughness was $22.6 \pm 3.6 \mu \mathrm{m}$ and CGS nano$\mathrm{TiO}_{2}$ eased off the pointed profile of the metallic coating leading to a value of $17.9 \pm 1.0 \mu \mathrm{m}$.

Figure 5 represents phase composition (XRD) of PEEK substrate, CGS $\mathrm{Ti}$ layer and CGS nano- $\mathrm{TiO}_{2}$ coating. It is

TABLE I. Nomenclature of the Spraying Conditions for the Factorial Design of Experiments and its Corresponding Ratios

\begin{tabular}{llll}
\hline & \multicolumn{2}{c}{$T\left({ }^{\circ} \mathrm{C}\right) / P($ bar $)$} \\
\cline { 2 - 4 } & & $15-25$ & $25-35$ \\
\hline$v_{\mathrm{g}}\left(\mathrm{mm} \mathrm{s}^{-1}\right) / d_{\mathrm{s}}(\mathrm{mm})$ & $4-8$ & $\mathrm{C} 350$ & $\mathrm{C} 351$ \\
& $8-12$ & $\mathrm{C} 352$ & $\mathrm{C} 353$ \\
\hline
\end{tabular}



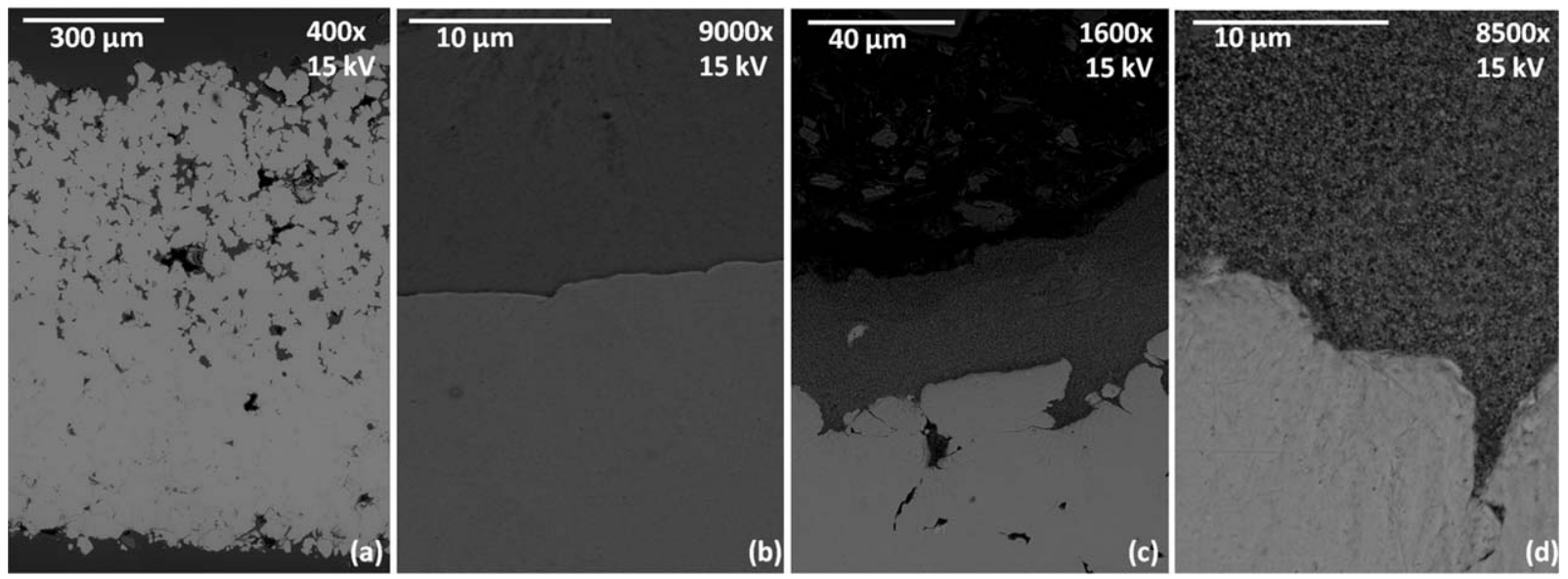

FIGURE 3. SEM micrographs: Cross-section area of CGS Ti bond coat (a) and CGS nano- $\mathrm{TiO}_{2}$ coating (c). Their respective interfaces are also detailed $(b, d)$.

possible to observe that all materials did not have the presence of impurities or undesired phase transformations.

\section{Biological response}

Cell viability. Results at the first day of culture regarding cell adhesion showed the same performance either for bulk polymer or both CGS coating materials (Figure 6). However, titanium layer and nanostructured titanium dioxide coating doubled cell viability of PEEK after 7 days. No significant differences could be observed when comparing metal and metal oxide. Capacity of cells to get adhered on a surface is determined by the adsorption of proteins that are present

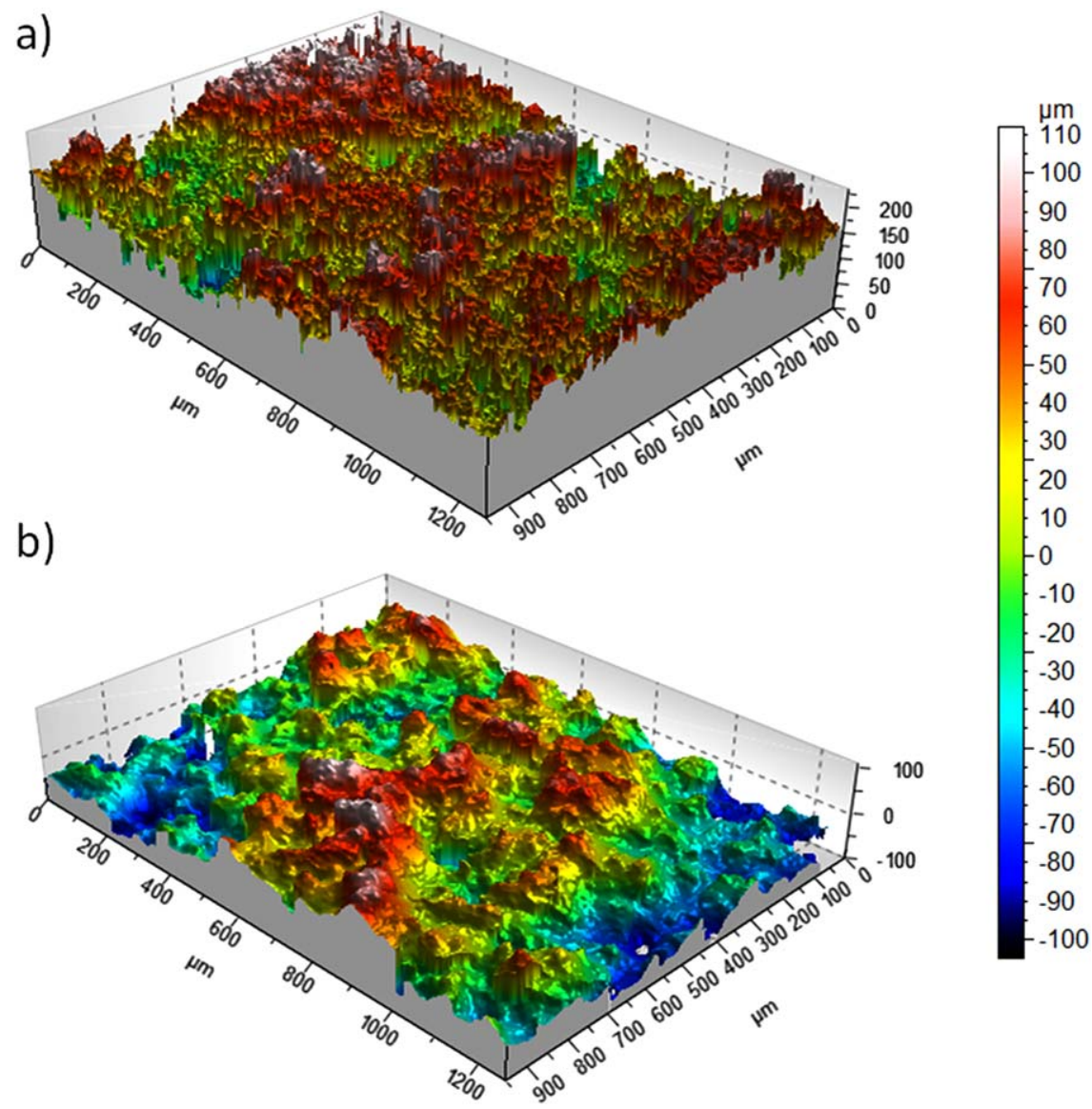

FIGURE 4. Confocal micrographs of rough surfaces based on CGS Ti layers (above) and CGS nano-TiO 2 (below). [Color figure can be viewed in the online issue, which is available at wileyonlinelibrary.com.] 


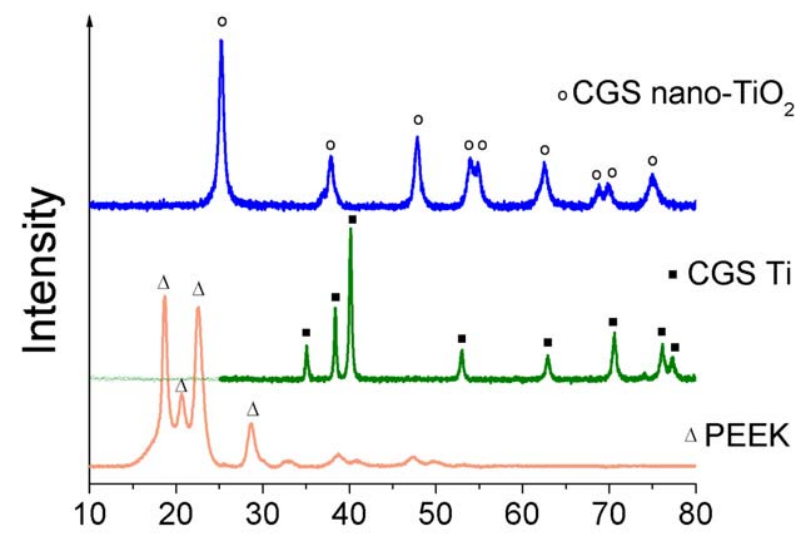

Angle $2 \theta$

FIGURE 5. XRD of PEEK ${ }^{25}$ CGS Ti layer, ${ }^{26}$ and CGS nano-TiO ${ }_{2}$ coating. ${ }^{27}$. [Color figure can be viewed in the online issue, which is available at wileyonlinelibrary.com.]

on the extracellular matrix (ECM). ${ }^{28}$ Surface stability provided by crystallographic planes of $\mathrm{TiO}_{2}$, commonly used in catalysis, may provide an ideal scenario for boosting desired preadsorption of organic molecules. Nevertheless, cell adhesion in nanostructured anatase did not increase compared to titanium. Some authors have reported that Ti biocompatibility is given by thin titanium dioxide layer formed at the top surface of metallic grains. ${ }^{29,30}$ Therefore, lack of difference observed between CGS coatings in this assay may be determined by coexistence of the above mentioned metal oxide monolayer in both materials, which would be in charge of equalizing the adsorption of proteins. The increase of MTT results at 7 days of CGS Ti and CGS nano- $\mathrm{TiO}_{2}$ are attributed to increased proliferation in this specimens compared to PEEK but it not reach to control results.

Furthermore, other authors have observed dependency of cell adhesion with the stiffness of the sample ${ }^{31}$; an

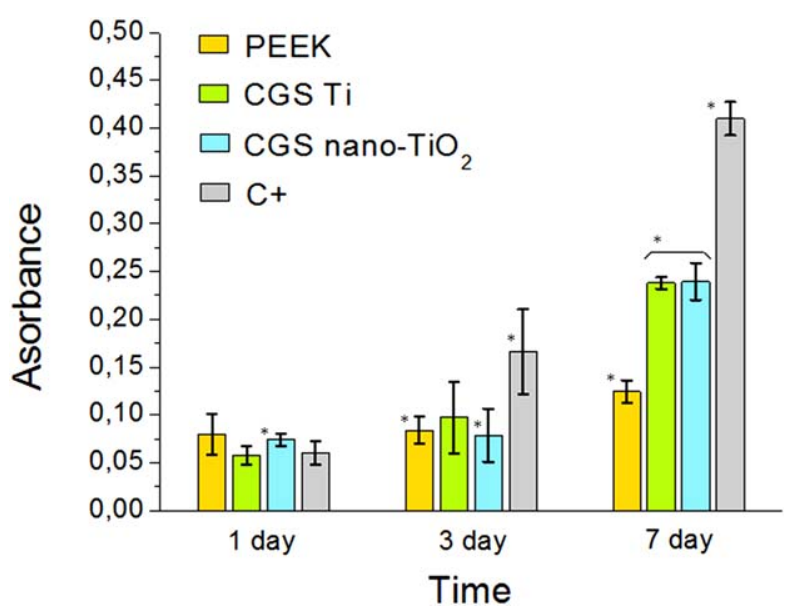

FIGURE 6. Cell viability results after 1, 3, and 7 days. Assays were developed on PEEK, CGS Ti layer and CGS nano-TiO ${ }_{2}$ coating, $n=7$. Significant differences among materials are marked with an asterisk. [Color figure can be viewed in the online issue, which is available at wileyonlinelibrary.com.]

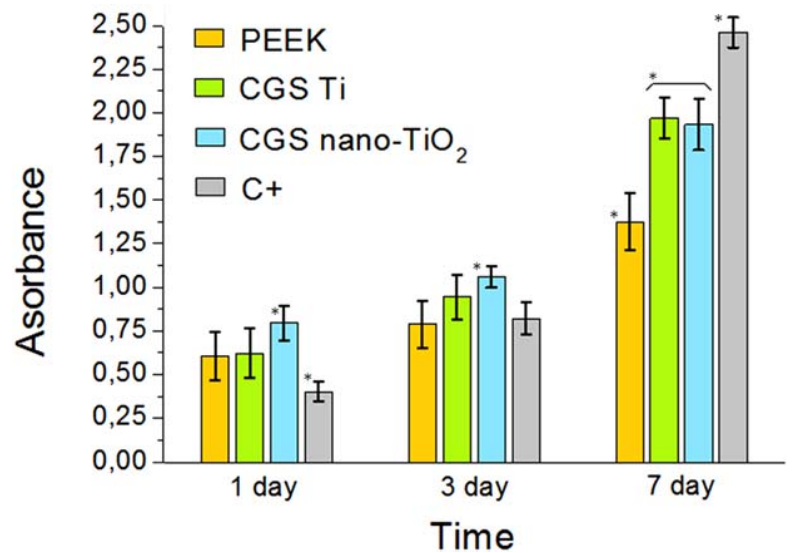

FIGURE 7. Cell proliferation results after 1, 3, and 7 days. Assays were developed on PEEK, CGS Ti layer and CGS nano-TiO ${ }_{2}$ coating, $n=7$. Significant differences among materials are marked with an asterisk. [Color figure can be viewed in the online issue, which is available at wileyonlinelibrary.com.]

increase in the Young modulus of the prosthesis may lead to better cell adhesion. Thus, rigid surfaces provided by CGS coatings compared to the original polymer could also contribute to an enhancement of cell parameters such as adhesion, proliferation, and differentiation.

Cell proliferation. Nanostructured $\mathrm{TiO}_{2}$ coatings had a slight proliferation increase on day 1 and 3 (Figure 7). As MTT results, both titanium and titanium dioxide showed superior performance on the seventh day compared to PEEK but less than control samples. Proliferation may be stimulated up to a certain value as long as roughness increases in Ti surfaces. ${ }^{32}$ Thus, differences in surface geometry between titanium and anatase could explain our results both cell adhesion/viability and proliferation. These results corroborate the MTT measurements suggesting clearly a high performance of Ti materials.

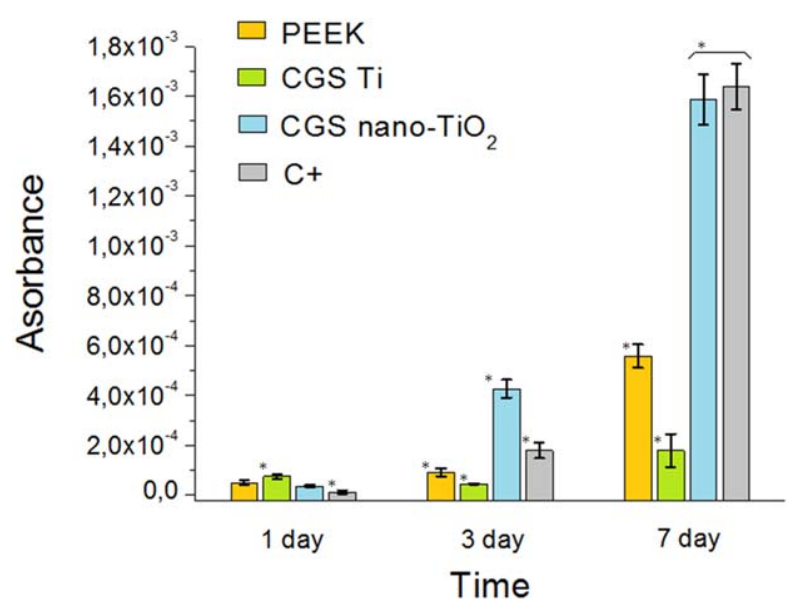

FIGURE 8. Obtained results in cell differentiation after 1, 3, and 7 days. Assays were developed on PEEK, CGS Ti layer and CGS nano$\mathrm{TiO}_{2}$ coating, $n=7$. Significant differences among materials are marked with an asterisk. [Color figure can be viewed in the online issue, which is available at wileyonlinelibrary.com.] 

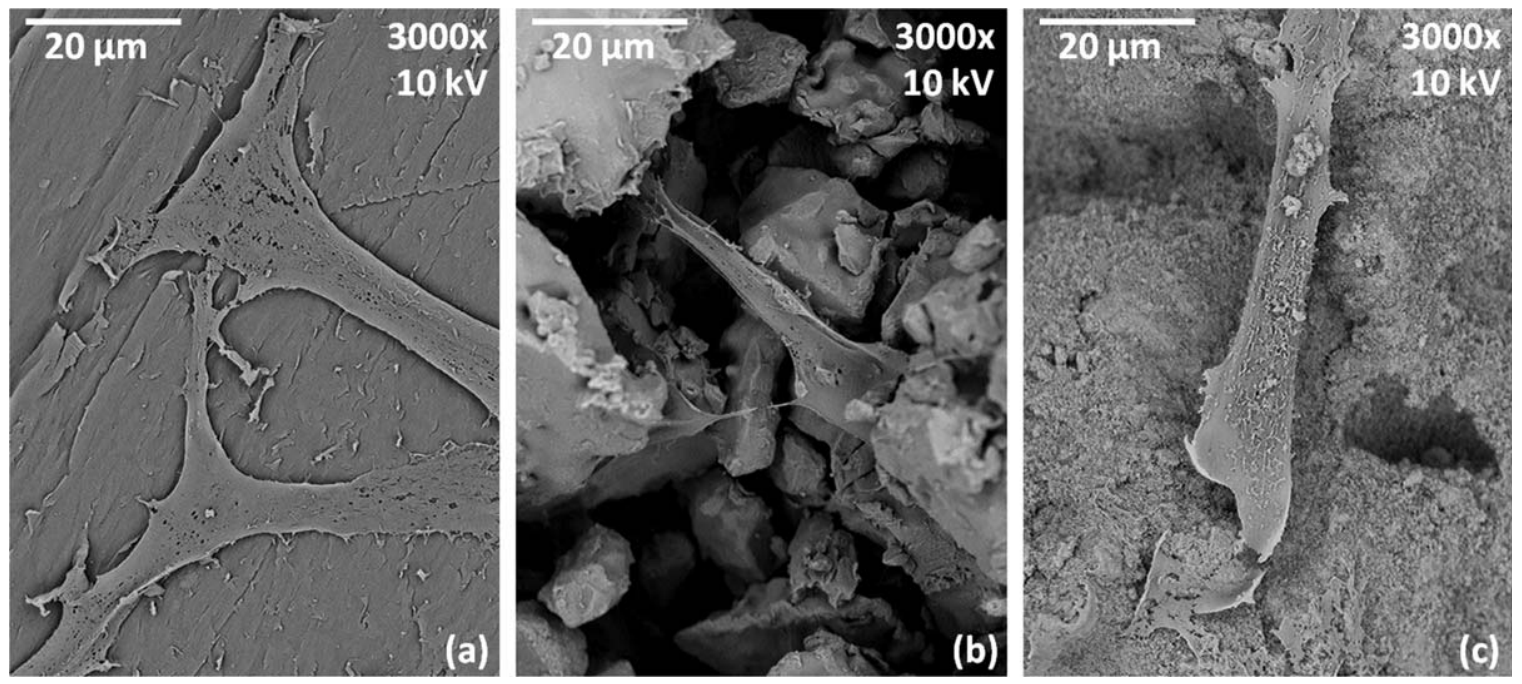

FIGURE 9. Top surface micrographs of cell cultures after 7 days on PEEK (a), CGS Ti layer (b), and CGS nano-TiO ${ }_{2}$ coating (c); adhered osteoblasts can be observed.

Cell differentiation. Alcaline phosphatase is highly expressed in differentiated osteoblasts and is currenly used as a marker of differentiation status. CGS nano- $\mathrm{TiO}_{2}$ showed a superior capacity of differentiating cells from third day of culture (Figure 8) compared to other materials tested. At 7 days of culture, $\mathrm{TiO}_{2}$ coatings had similar behaviour than control cultures. In contrast, titanium layers showed the worsts results. Last analysis revealed that nanostructured metal oxide coating had an excellent ability in cell differentiation, obtaining one order of magnitude above the value of PEEK.

These results give evidence that surface roughness provided by nanostructured scaffolds may also have a crucial role in the interaction between cells and solid substrates. ${ }^{33}$ Nanotextures at the surface of the coating resembled the nanoarchitecture of natural ECM, which may facilitate differentiation. Besides, other authors have reported that $\mathrm{TiO}_{2}$ coatings with nanometer thickness enhance the biological response of microroughened titanium surfaces in terms of cell differentiation. ${ }^{34}$ In this study, roughness of titanium and titanium dioxide coatings built-up by CGS were not quite dissimilar (measured values are shown in Cell Viability section). Nevertheless, it is worthy to understand the distinctiveness between microroughness and nanoroughness. Thus, biomimetic superficial features of nano- $\mathrm{TiO}_{2}$ would be in charge of developing successful results in cell differentiation.

Cell observation. Geometry and aspect of the cells on PEEK and coating materials was studied after 1, 3, and 7 days of culture. Figure 9 shows top surface micrographs of polymer, CGS Ti and CGS nano- $\mathrm{TiO}_{2}$ with corresponding adhered cells after 7 days of cell culture. In all cases, typical osteoblastic shape was observed with similar spreading among materials tested. In spite of differences in parameters such as cell adhesion, proliferation, or differentiation, it was unfeasible to correlate the obtained values with scanning electron micrographs. Punctual covering was spread on the polymer, coating metal and metal oxide without noteworthy divergences. In our materials, SEM methodology was not able to detect minimal changes in cell conformation and focal adhesions between samples.

\section{CONCLUSIONS}

Homogeneous nanostructured anatase coatings were applied onto biocompatible polyetheretherketone (PEEK) by cold gas spray (CGS). CGS titanium layers were used as bond coat for easing the adhesion of ceramic particles, which could provide a surface able to ease chemical bonding with anatase particles. CGS spraying conditions were adequately adjusted in order to improve the adhesion of nanostructured metal oxide on Ti bond coat. Crystalline structure of titanium was unaffected during the coating process and titanium dioxide preserved its nanostructure. Biological response of the Ti surfaces was significantly better than PEEK from 3 days of culture regarding cell viability and proliferation. However, in terms of osteoblast differentiation, polymer coated with nanostructured titanium dioxide showed optimal results. Surface micro- and nanoroughness may be a significant parameter to be controlled during CGS process so as to optimize the bioactivity of these coating materials.

\section{REFERENCES}

1. Spetzger U, Vougioukas V, Schipper J. Materials and techniques for osseous skull reconstruction. Min Inv Ther 2010;19:110-121.

2. Available at: http://www.invibio.com/ (Acessed 08/02/2013).

3. Ponnappan RK, Serhan H, Zarda B, Patel R, Albert T, Vaccaro AR. Biomechanical evaluation and comparison of polyetheretherketone rod system to traditional titanium rod fixation. Tspine $\mathrm{J}$ 2009;9:263-267.

4. Kurtz SM, Devine JN. PEEK biomaterials in trauma, orthopedic, and spinal implants. Biomater 2007;28:4845-4869.

5. Toth JM, Wang M, Estes BT, Scifert JL, Seim HB III, Turner AS. Polyetheretherketone as a biomaterial for spinal applications. Biomaterials 2006;27:324-334. 
6. Noiset O, Henneuse C, Schneider YJ, Marchand-Brynaert J. Surface Reduction of Poly(aryl ether ether ketone) Film: UV Spectrophotometric, 3H Radiochemical, and X-ray Photoelectron Spectroscopic Assays of the Hydroxyl Functions. Macromolecule 1997;30:540-548.

7. Noiset O, Henneuse C, Schneider YJ, Marchand-Brynaert J. Fibronectin adsorption or/and covalent grafting on chemically modified PEEK film surfaces.. J Biomat Sci Polym Ed 1999;6:657-677.

8. Abu Bakar MS, Cheng MHW, Tang SM, Yu SC, Liao K, Tan CT, Khor KA, Chean P. Tensile properties, tension-tension fatigue and biological response of polyetheretherketone-hydroxyapatite composites for load-bearing orthopedic implants. Biomaterials 2003 ; 24:2245-2250.

9. Ramakrishna S, Mayer J, Wintermantel E, Leong KW. Biomedical applications of polymer-composite materials: a review. Comp Sci Tech 2001;61:1189-1224.

10. Converse GL, Yue W, Roede RK. Processing and tensile properties of hydroxyapatite-whisker-reinforced polyetheretherketone. Biomaterials 2007;28,6:927-935.

11. Zheng $X B$, Ding $C X$. Characterization of plasma-sprayed hydroxyapatite/ $/ \mathrm{TiO}_{2}$ composite coatings. J Therm Spr Tech 2000;4:520-525.

12. Lu YP, Li MS, Li ST, Wang ZG, Zhu RF. Plasma-sprayed hydroxyapatite+titania composite bond coat for hydroxyapatite coating on titanium substrate. Biomaterials 2004; 18:4393-4403.

13. Li H, Khor KA, Cheang P. Titanium dioxide reinforced hydroxyapatite coatings deposited by high velocity oxy-fuel (HVOF) spray Biomaterials 2002;23:85-91.

14. Gaona M, Lima RS, Marple BR. Nanostructured titania/hydroxyapatite composite coatings deposited by high velocity oxy-fuel (HVOF) spraying. Mater Sci Eng A 2007;458:141-149.

15. Marple BR, Lima RS, Li H, Khor KA. Biomimetic ceramic surfaces produced by thermal spraying nanostructured titania: A coating alternative to hydroxyapatite on orthopedic implants? Key Eng Mater 2006;309-311:739-742.

16. Lima RS, Dimitrievska S, Bureau MN, Marple BR, Petit A, Mwale

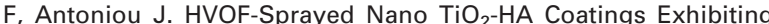
Enhanced Biocompatibility. J Therm Spray Tech 2010;19:336-343.

17. Champagne V. The Cold Spray Materials Deposition Process: Fun damentals and Applications. Cambridge, England: Woodhead Publishing in Materials; 2007.

18. Pawlowski L. The Science and Engineering of Thermal Spray Coatings. Chichester, England: Wiley; 2008.

19. Tjitra Salim N, Yamada M, Nakano H, Shima K, Fukumoto M. The Synthesis of Titanium Dioxide Powders for Cold Spray, Therma Spray 2011. Proceedings of the International Thermal Spray Conference, B.R. Marple, Ed., September 27-29, 2011 (Hamburg, Germany), ASM International, 2011.

20. Nacher M, Aubia J, Serrano S, Marinoso ML, Hernandez J, Bosch J, Diez A, Puig JM, Lloveras J. Effect of cyclosporine A on normal human osteoblasts in vitro. Bone Miner 1994;26:231-243.
21. Sieuwerts AM, Klijn JGM, Peters HA, Foekens JA. The MTT Tetrazolium Salt Assay Scrutinized: How to Use this Assay Reliably to Measure Metabolic Activity of Cell Cultures in vitro for the Assessment of Growth Characteristics. Eur J Clin Chem Clin Biochem 1995;33:813-823.

22. Lee JH, Jang HL, Lee KM, Baek HR, Jin K, Hong KS, Noh JH, Lee HK. In vitro and in vivo evaluation of the bioactivity of hydroxyapatitecoated polyetheretherketone biocomposites created by cold spray technology. Acta Biomat 2013;9:6177-6187.

23. Gardon M, Latorre A, Torrell M, Dosta S, Fernández J, Guilemany JM. Cold Gas Spray Titanium coatings onto a biocompatible polymer. Mater Lett 2013;106:97-99.

24. Gardon M, Fernández-Rodríguez C, Garzón Sousa D, DoñaRodríguez JM, Dosta S, Cano IG, Guilemany JM. Photocatalytic activity of nanostructured anatase coatings obtained by Cold Gas Spray. J Therm Spr Tech. DOI: 10.1007/s11666-014-0087-0.

25. Dupont O, Ivanov DA, Jonas AM, Legras R. Adaptation of the Rietveld method to the characterization of the lamellar microstructure of polymers. 2. Influence of a tilt of chain axes versus the normal to basal planes of crystalline lamellae. J Appl Cryst 1999;32:497-504.

26. Wood RM. The Lattice Constants of High Purity Alpha Titanium. Proc Phys Soc 1962;80:783.

27. Burdett JK, Hughbanks T, Miller GJ, Richardson JW, Smith JV. Structural-electronic relationships in inorganic solids: powder neutron diffraction studies of the rutile and anatase polymorphs of titanium dioxide at 15 and 295 K. J Am Chem Soc 1987;109: 3639.

28. Gumbiner BM. Cell Adhesion: The Molecular Basis of Tissue Architecture and Morphogenesis. Cells 1996;84,3:345-357.

29. Long $M$, Rack HJ. Titanium alloys in total joint replacement-a materials science perspective. Biomaterials 1998;19:1621-1639.

30. Wu LN, Genge BR, Wuthier RE. Micropatterned $\mathrm{TiO}_{2}$ effects on calcium phosphate mineralization. Mater Sci Eng C 2009:8:2355-2359.

31. Koufaki N, Ranella A, Aifantis KE, Barberoglou M, Psycharakis S, Fotakis C, Stratakis E. Controlling cell adhesion via replication of laser micro/nano-textured surfaces on polymers. Biofab 2011;3: 045004.

32. Mustafa K, Wennerberg A, Wroblewski J, Hultenby K, Lopez BS, Arvidson K. Determining optimal surface roughness of $\mathrm{TiO}_{2}$ blasted titanium implant material for attachment, proliferation and differentiation of cells derived from human mandibular alveolar bone. Clin Oral Implant Res 2001;12:515-525.

33. Zhao C, Tan A, Pastorin G, Ho HK. Nanomaterial scaffolds for stem cell proliferation and differentiation in tissue engineering. Biotech Adv 2013:31:654-668.

34. Sugita $Y$, Ishizaki $K$, Iwasa F, Ueno T, Minamikawa H, Yamada M, Suzuki T, Ogawa T. Effects of pico-to-nanometer-thin $\mathrm{TiO}_{2}$ coating on the biological properties of microroughened titanium. Biomaterials 2011;32:8374-8384. 